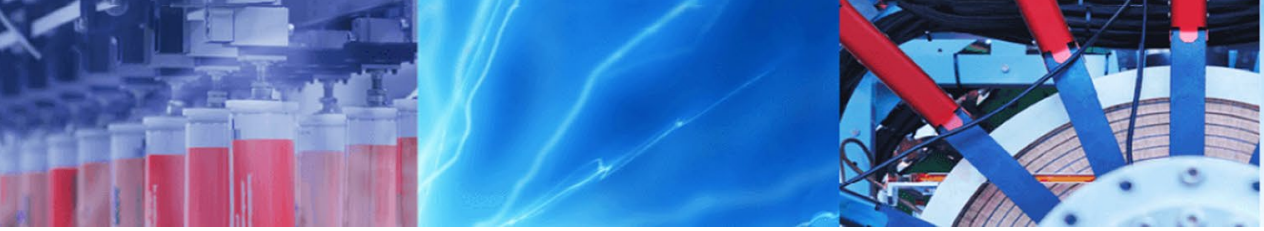

Research Article

\title{
Fault detection technique for modified cascaded half-bridge multi-level inverter with polarity changer in pv grid system
}

\author{
Ujjval B Vyas ${ }^{1}$ (D) Varsha A Shah ${ }^{1} \cdot$ Srivani S G ${ }^{2}$
}

Received: 20 October 2020 / Accepted: 15 April 2021

Published online: 29 April 2021

(c) The Author(s) 2021 OPEN

\begin{abstract}
Multilevel Inverters (MLI) are a viable option for a filter-less and transformerless photovoltaic system for direct grid integration, reducing losses, space and cost provided the issues of control and reliability are resolved. A modified cascaded half-bridge MLI with polarity changer is proposed with a reduced number of switches, thereby reducing control complexity. The proposed converter is designed for both seven-level and nine-level topologies. Selective harmonic elimination has been adopted to switch converter and the transcendental equations are solved by the gravitational search algorithm. The THD for nine-level configuration is $7.94 \%$ and $5.86 \%$ with MPPT and DC source inputs, respectively. The analysis on the open-circuit fault of switches confirms the presence of only five critical switches irrespective of the number of increase in levels, thereby requiring only five redundant switches at the Polarity Changer. The output voltage waveform is subjected to multiresolution analysis for feature extraction of voltages under various irradiance and temperature conditions. A conditions based fault detection algorithm is developed based on the observations of energies of signals to detect the open circuit fault in switches. Based on the comparative analysis, the proposed converter has fewer controlled switches for nine levels or higher configurations than other topologies. Apart from this, the high reliability due to inherent fault isolation capability restricted to half-bridge compared to different $\mathrm{MLI}$ topologies shows its superiority. For a nine-level MLI proposed topology reduces the cost considering redundancies for FDI in range of $67-30 \%$ depending on the topology for comparision. The system is simulated using MATLAB -Simulink and further validated by experimental results.
\end{abstract}

Keywords Modified cascaded half-bridge multilevel inverter with polarity changer - Selective harmonic elimination . Fault detection technique $\cdot$ Multi resolution analysis

\section{Introduction}

In recent years, the inversion technique using the multilevel configuration known as Multilevel Inverters (MLI) has been widely adopted due to its low Total Harmonic Distortion (THD) at a low switching frequency, a critical characteristic for grid synchronization of Photo Voltaic (PV) power plants. MLI's concept is based on the production of stepped output voltage and is approximated to a sinusoidal voltage with an increase in the number of steps. The stepped response is obtained by an ensemble of properly placed power electronic devices with switching either isolated DC sources [1] or multiple DC sources obtained through spilt capacitors by diode clamping [2] otherwise by flying capacitors [3]. Apart from lower THD, MLI rises above the restrictions due to the limited rating of power semiconductors, reduces $\frac{d V}{d t}$ stress of switch and issues due to common voltage $[4,5]$. The International standards allow direct grid connection of MLI for medium and high power applications without isolation [5], thus providing a

$\triangle$ Ujjval B Vyas, ujjvalbvyas@gmail.com; Varsha A Shah, vas@eed.svnit.ac.in; Srivani S G, srivanisg@rvce.edu.in| ${ }^{1}$ Sardar Vallabhbhai National Institute of Technology, Surat, India. ${ }^{2} \mathrm{R} V$ College of Engineering, Bangalore, India. 
viable option for a filter-less and transformerless system. The adoption of this system reduces the losses, space and cost. These advantages can be realized provided the following challenges are resolved:

- The increase in controlled switches reduces the THD thereby, increasing the control complexity and cost in terms of requirements in driver circuits.

- The PV system is designed for long durations; however, the low-reliability power electronic devices reduce the converter's reliability.

The control complexity challenge due to numerous switches is solved by developing the Reduced Part Count MLI (RPC-MLI). The adoption of RPC-MLI for PV systems requires a careful study of the PWM technique to reduce the THD content, a proper control algorithm for grid integration and a fault detection algorithm. Both PWM techniques and power control algorithms for grid integrations have been vastly studied $[6-8]$. A survey in $[9,10]$ concluded that power electronic switches are more susceptible to failure in any system. These faults play a vital role as the number of high powered grid integrated PV plants increases. The fault of switches in a power electronic converter can hinder the plant operation and without a proper algorithm to address the reliability a huge block of power is suddenly removed from the grid. These faults in switches may cause many issues related to the grid's stability as a massive portion of power is suddenly unavailable. The converters along with control algorithms that mitigates these issues in smart grid are coined as smart converters in [11]. The algorithms associated with increasing the converter reliability are often defined as Fault Detection and Isolation (FDI) algorithms.

The Fault Detection and Isolation (FDI) scheme is defined in [12] as "a monitoring system that is used to detect faults and diagnose their location and significance in a system." Various methodologies adopted in literature for FDI schemes such as the Quantitative approach, Qualitative approach and soft computing approach have been discussed in [13]. The implementation of the FDI scheme increases the reliability of a Cascaded $\mathrm{H}$-Bridge MLI (CHBMLI) from 86 to 99\% [14] and usage of Reduced Part Count (RPC) MLI reduces the complexity of the circuit [15]. This paper concentrates on the development of the FDI scheme to RPC- MLI. In literature, FDI scheme is mostly implemented using soft computing techniques such as a neural network to classify faults. The [16] discusses the FDI scheme by placing the sensors to sensors output voltage and current at each bridge. Even though methodology is simple for execution an extra cost is incurred for the sensors. In literature the FDI scheme has been based on either rule based method or soft computing base method. In [17] a FDI scheme based on the mean voltages at each bridge has been studied. In [18, 19], a combination of soft computing technique and a simplified rule based algorithm is adopted to detect an open-circuit fault in switches for symmetric operation of CHB-MLI. [20] proposes an optimization based neural network for development of FDI scheme for CHBMLI. In [21] an neural network based FDI scheme has been discussed for the asymmetric operation of CHBMLI. The researchers have also tried to solve the issue of reliability of modification in the topology. In [22] an additional cross coupled CHB MLI unit is incorporated in CHBMLI to increase the reliability. The increase in reliability also causes increase in cost. [23] proposes a fault tolerant MLI that includes an redundant leg consisting of 6 switches. This redundancy increases with the increase in the number of levels.

Based on the literature survey carried for the isolation of faulty switches in the circuit, the following are necessary conditions to be satisfied.

- There must be a closed-loop path in the circuit after isolation of fault.

- A closed-loop is not formed in certain circuits when specific switches under fault conditions, such switches are referred to as critical switches. A redundant switch is required to replace the faulty switch and such switches are termed as critical switches in this study.

- The economic consideration dictates the critical switches to be less.

- In a few cases, additional switches are also utilized to isolate the faulty switch [24].

The selection of a proper RPC-MLI for the issue of reliability requires satisfaction of the above conditions. In Ref. [25], a cascaded connection of half-bridge circuits is connected to a full-bridge inverter termed as Polarity Changer (PC) to produce an alternating waveform from the unidirectional output. This circuit has ' $m+3$ ' switches where ' $m$ ' represents number of levels. The circuit consists of 8 switches for 5 level output with six critical switches, of which four are in PC and one in each cascaded half-bridge. thus requiring redundancy, increasing with the number of switches. In Ref. [26] a 5 level unidirectional staircase waveform is produced by a circuit similar to a bridge circuit where the load is replaced by switch and DC sources replace two diagonal switches. An alternating waveform is obtained by a PC similar to 15 . A Switch is placed for the freewheeling action of PC. This circuit has ' $m+3$ ' switches where ' $m$ ' represents number of levels.

The circuit has eight switches for five-level output; six are critical switches; therefore, redundant switches are required in the circuit, which increases with the number of levels. Ref. [27] Utilizes two dc sources with two 
unidirectional and two bidirectional switches to generate a positive staircase waveform. This circuit is connected to a PC similar to Ref. [25]. A switch is placed for the freewheeling action of PC. This circuit has $\frac{3(m+5)}{2}$ switches where ' $m$ ' represents number of levels. The circuit has eight switches, of which two are bidirectional for five-level output, and all of them are critical switches, so there must be redundant switches placed in the circuit. This redundancy increases with an increase in levels. Ref. [28] utilizes six switches and two DC sources for five-level operations. In this circuit, all the switches are critical, but if there is a fault in switching, then the DC source could be bypassed using another switch that was dormant until fault occurrences. This solution fails when two adjacent switches are under fault conditions. This circuit has $\frac{3(m-1)}{2}$ switches where ' $m$ ' represents number of levels. Ref. [29] utilizes 2 DC source six switches and eight diodes for five-level operations. In this circuit, switches along with all the diodes are critical and require redundancy. This circuit has $\frac{3(m-1)}{2}$ switches where ' $m$ ' represents number of levels. Ref. [30] utilizes two DC source and six switches for five-level operation. In this circuit, all are critical switches, so when a fault occurs in these switches, an alternate circuit is not possible, so there must be redundant switches placed in the circuit.

Based on the survey provided, a conclusion is derived that the number of critical switches are increasing with increase in the level. This requires a high cost as the system requires many redundancies and the control circuit becomes more complicated. Therefore, development of a RPC-MLI with reduced critical number of switches is a priority to develop a transformerless and filter-less PV grid system. This paper proposes a modified form of Cascaded Half-Bridge MLI with Polarity Changer (PC) from Ref. [25]. As the proposed system requires only unidirectional converter the switch present in lower part of the half bride is replaced by diode. This reduces the requirement of high cost controlled critical switches.

This circuit has an inherent capability of fault isolation of switches in the cascaded half-bridge, that has been validated through simulation and experimentation. The circuit consists of 5 critical switches irrespective of the number of levels, thereby reducing the cost for redundancy with respect to CHBMLI and RPC-MLI circuits. The system is designed and simulated for a three-phase system with PV as an input. The article concentrates only on the open circuit faults of switches in the proposed converter, which are difficult to trace than short circuit faults. Since the redundant switches must be incorporated in the switching circuit during an open-circuit fault in switches and the isolated switches are to be restored, a fault detection algorithm is proposed for modified MLI. Therefore, the contributions of the article can be summarized as follows:
- Proposes a Modified Cascaded Half Bridge MLI with Polarity Changer (MChBMLI with PC) that has higher reliability and less complexity as the total number of controlled switches are less compared to other RPCMLI.

- Adoption of Gravitational Search Algorithm (GSA) for solving of Selective Harmonic Elimination (SHE)

- Development of rule based FDI algorithm based on multi resolution analysis for detection of open circuit faults in switches for proposed circuit.

The article is organized into seven sections. The Sec- 2 describes the symmetric operation mode of the proposed Modified Cascaded Half-Bridge MLI with PC. The Sec-3 describes the design of the topology, and the Sec- 4 provides the simulation results for both three phase and single phase. The simulations are carried for both three phase and single phase system. This section provides results for irradiance of $1000 \mathrm{~W} / \mathrm{m} 2$ and temperature $25^{\circ} \mathrm{C}$. A simulation study is carried by creation of open circuit faults. Based on the inferences from the results of Sec-4, a Fault Detection algorithm is developed in Sec-5. The Sec- 6 validates the algorithm with experimental results obtained from the laboratory. The Sec-7 provides a comparative analysis of proposed MLI with MLI present in literature. A conclusion to the article is provided in sec- 8 .

\section{System description}

The grid connected PV system requires tracking of maximum power point and a grid integration algorithm. The maximum power point operation is generally obtained by two methodologies. In the first methodology incorporating the MPPT algorithm in the grid integration as described in [31].The second method is to adopt the conventional methodology of utilizing a DC-DC converter for MPPT algorithm as in [31]. The present work adopts the tracking of maximum power point through DC-DC converter as shown in Fig. 1. The three phase PV system consist of three blocks that produces an alternating voltage for each phase. The control algorithm for grid integration provides modulation index for PWM Technique.

The cascaded half bridge MLI with PC is shown in Fig. 3a. The proposed Modified Cascaded Half-Bridge MLI with PC consist of three DC supplies, eight switches and three diodes for a seven-level operation is shown in Fig. 2b. The proposed circuit is obtained by replacing the bidirectional switches in the half bridge $\left(\mathrm{S}_{1}, \mathrm{~S}_{1}^{\prime}, \mathrm{S}_{2} \mathrm{~S}_{2}, \mathrm{~S}_{3}\right.$ and $\mathrm{S}_{3}^{\prime}$ ) in Fig. 2a with unidirectional switches and diodes as shown in Fig. 3b. A freewheeling switch ' $F$ ' is placed for the freewheeling of inductor current. The modifications in the topology of Fig. 3a limits its usage only for unidirectional 


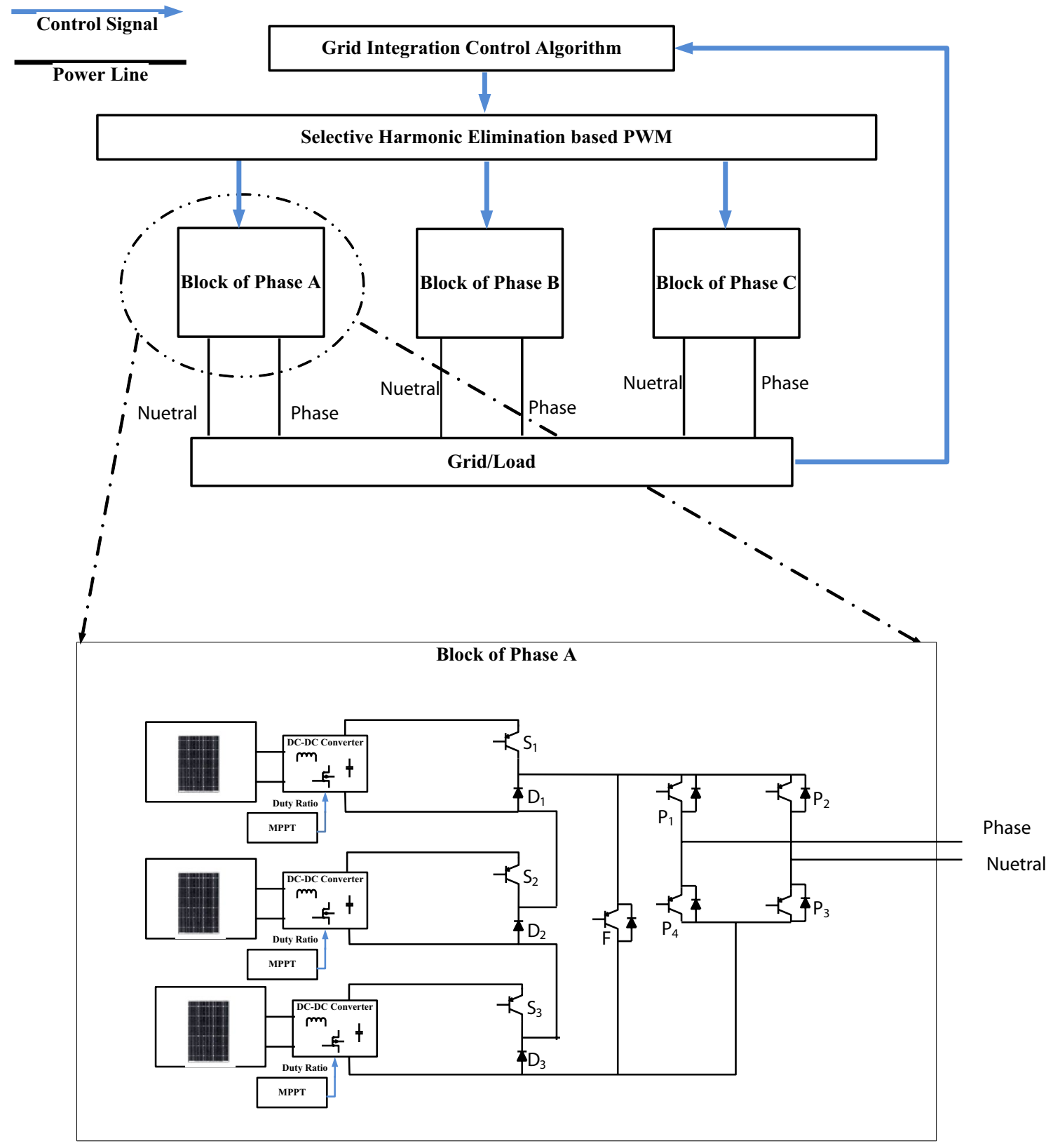

Fig. 1 Block diagram representing the system

applications and cannot function properly loads with for very low power factors. As the PV grid system is a unidirectional load and the IEEE standards dictates the operation has to near unity power factor the proposed converter suits appropriately despite of its limitations. The incorporated modifications has removed the critical switches in Fig. $2 a\left(\mathrm{~S}_{1}{ }_{1}, S^{\prime}{ }_{2}\right.$, and $\left.\mathrm{S}_{3}{ }_{3}\right)$ that increase with increase in level. In the proposed converter the increase in level is obtained by incorporating aa DC source is parallel with combination of non-critical switch in series with diode.

The cascaded connection of modified half-bridge circuits provides a positive voltage waveform with a staircase shape. A Polarity Changer (PC) interpreted as a full-bridge inverter is utilized to produce an alternating waveform along with a switch $\mathrm{F}$ that provides a freewheeling action for any load without a unity power factor. The switches $\mathrm{S}_{1}, \mathrm{~S}_{2}$ and $\mathrm{S}_{3}$ have controlled switches of each half-bridge, respectively. When the switches $S_{1}, S_{2}$ and $S_{3}$ are on, the Diodes $D_{1}, D_{2}$ and $D_{3}$ are in reverse bias. This article concentrates on the symmetric mode of operation.

In the symmetric mode of operation, the DC Voltage sources have the same voltage $\left(V_{1}=V_{2}=V_{3}=V\right)$; thus, the maximum number of steps obtained is seven viz., $+3 \mathrm{~V},+2 \mathrm{~V},+\mathrm{V}, 0,-\mathrm{V},-2 \mathrm{~V}$ and $-3 \mathrm{~V}$. The voltage $+\mathrm{V}_{1}$ is 
Fig. 2 a circuit diagram of Cascaded Half Bridge MLI with Polarity Changer b Circuit diagram of Modified cascaded half-bridge MLI with PC for seven levels $\mathbf{c}$ Flow of current in the circuit during $+\mathrm{V}_{1}$ d Flow of current during $+\left(\mathrm{V}_{1}+\mathrm{V}_{2}\right)$

e Flow of current dur-

ing $+\left(\mathrm{V}_{1}+\mathrm{V}_{2}+\mathrm{V}_{3}\right)$ f Flow of current during $0 \mathrm{~V}$ and the current flowing through Diodes of $\mathrm{P}_{1}$ and $\mathrm{P}_{3} \mathbf{g}$ Flow of current in the circuit during $0 \mathrm{~V}$ and the current flowing through diodes of $\mathrm{P}_{2}$ and $\mathrm{P}_{4}$

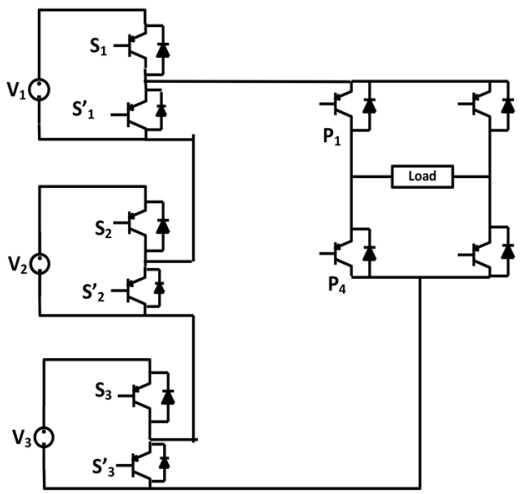

(a)

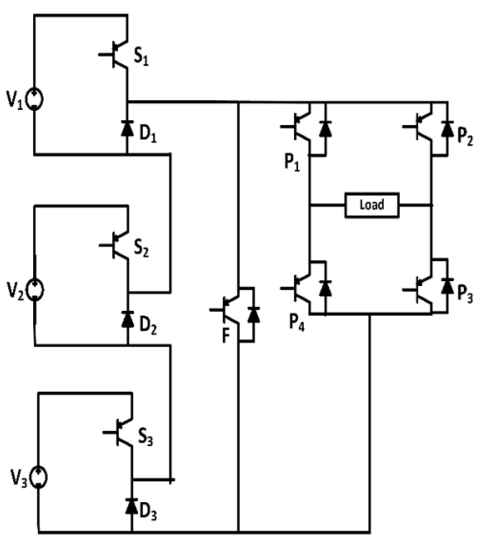

(b)

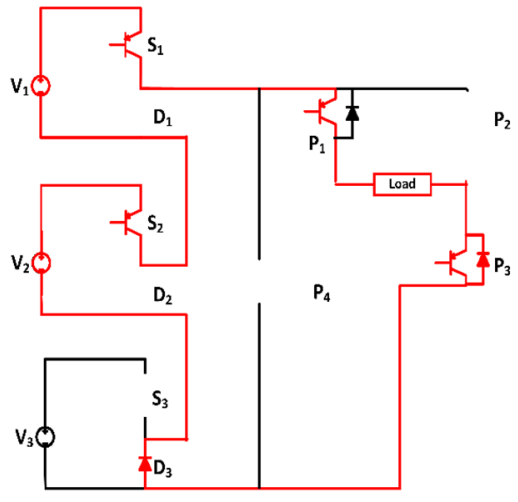

(d)

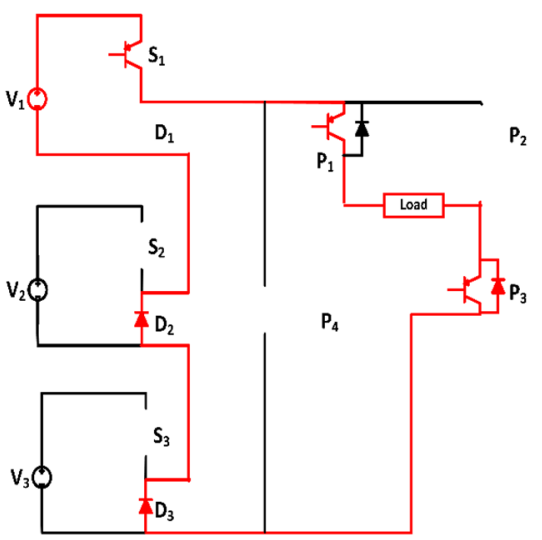

(c)

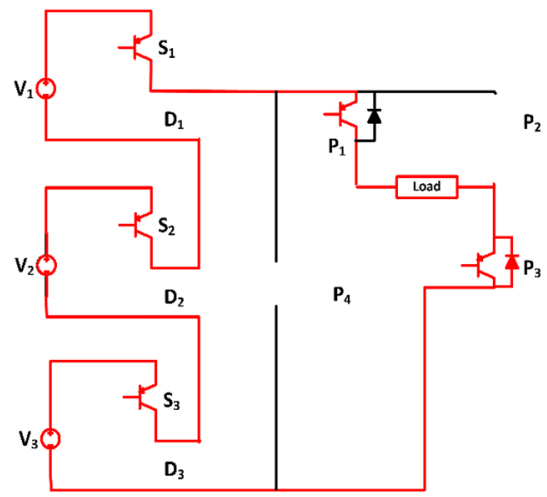

(e)

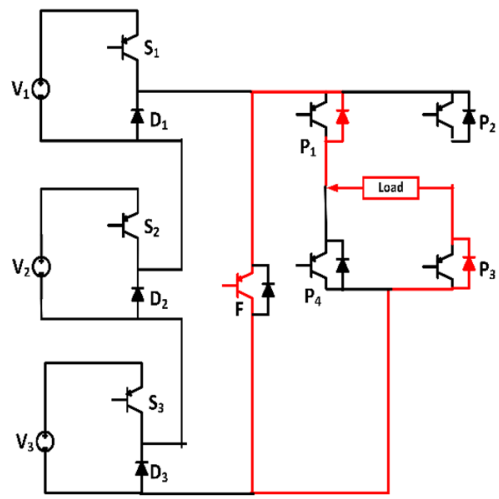

(f)

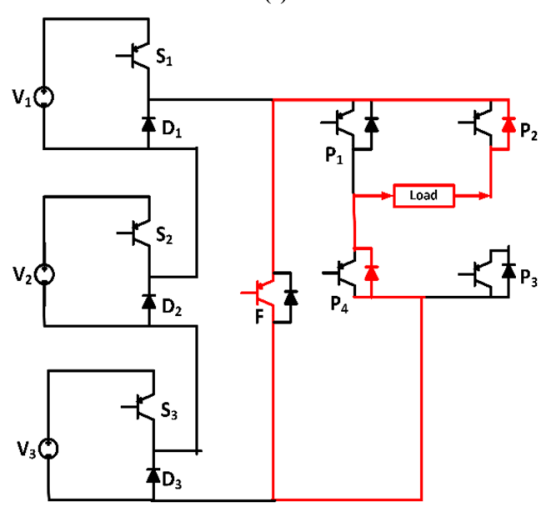

(g) 
Fig. 3 Graph of number of switches vs. number of levels for circuits of [25-30]

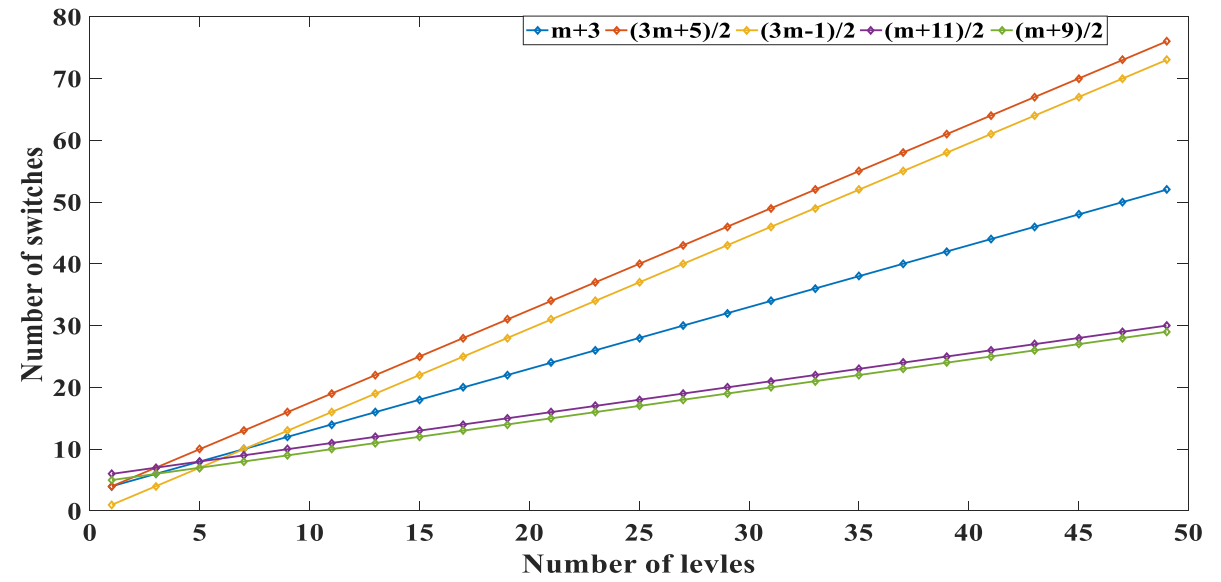

obtained when switches $\mathrm{S}_{1}, \mathrm{P}_{1}$ and $\mathrm{P}_{3}$ are turned on. During this state the diodes $D_{2}$ and $D_{3}$ are forward bias while the Diode $D_{1}$ is reverse biased as switch $S_{1}$ is on as shown in Fig. 2b. Similarly, voltages $+V_{2}$ and $+V_{3}$ is obtained when switches $S_{2}, S_{1}$ are on and switches $S_{1}, S_{2}$ and $S_{3}$ are on respectively with $P_{1}$ and $P_{3}$ in on condition as shown in Fig. 2c, d.

The negative polarity of output voltage is obtained with same switching while in Polarity Changer switches $P_{2}$ and $\mathrm{P}_{4}$ are on. At the end of the positive cycle, even though switches $\mathrm{P}_{2}$ and $\mathrm{P}_{4}$ are provided with gating signals, the current in RL load prevents the switches from turning on and the current finds the path of body diodes of $\mathrm{P}_{1}$ and $\mathrm{P}_{3}$ through switch F, as shown in Fig. 2e. Figure 2e, f represent the current flow when an RL load is connected and the inductor is discharged during $0 \mathrm{~V}$. Similarly, during the end of the negative cycle, the current travels through the body diodes of $\mathrm{P}_{2}$ and $\mathrm{P}_{4}$. The switching table for the symmetric operation of the proposed circuit is shown in Table 1. The total number of controlled switches in the circuit is $\left(\frac{m+9}{2}\right)$ where ' $m$ ' is number of levels and is an odd number greater than two. This is the least number of switches compared to circuits in discussed in Sec-1, represented in a graph shown in Fig. 3.

\section{Design of modified cascaded half-bridge mli with polarity changer}

The design of a system consisting of modified MLI, load and PV system is described in this section. The design is carried out with considerations of PV power plants. A Soltech 1STH-250WH has been selected for simulation purpose. The power-voltage characteristics of the panel for different irradiance and temperature is shown in Fig. 4a, $b$ respectively. The maximum open circuit voltage $\left(V_{o c}\right)$ is kept at $37.3 \mathrm{~V}$ and short circuit current $\left(\mathrm{I}_{\mathrm{sc}}\right)$ is considered $8.45 \mathrm{~A}$ for each panel for the experimental purpose. The voltage at maximum power for PV panel as per the changes of temperature and irradiance is shown in Table 2 .

The proposed modified multilevel inverter involves selecting switching angles, selecting switch ratings, and designing a snubber circuit. The switching angles are selected by the SHE method. The equations defining fundamental components and harmonic components are found by applying Fourier transform on output waveform and are shown in Eqs. 1, 2, and 3 for seven level and Eqs. 4, 5,6 , and 7 for nine level.

For seven-level

$\cos \theta_{1}+\cos \theta_{2}+\cos \theta_{3}=3 M$
Table. 1 Switching table for the symmetric mode of operation for proposed circuit (seven-level operation)

\begin{tabular}{lllllll}
\hline S. No & $\mathrm{P}_{1}$ and $\mathrm{P}_{3}$ & $\mathrm{P}_{2}$ and $\mathrm{P}_{4}$ & $\mathrm{~S}_{1}$ & $\mathbf{S}_{\mathbf{2}}$ & $\mathbf{S}_{\mathbf{3}}$ & $\mathbf{F}$ \\
\hline$+3 \mathrm{~V}$ & 0 & 1 & 1 & 1 & 1 & 0 \\
$+2 \mathrm{~V}$ & 0 & 1 & 1 & 1 & 0 & 0 \\
$+\mathrm{V}$ & 0 & 1 & 1 & 0 & 0 & 0 \\
0 & $1 / 0$ & $0 / 1$ & 0 & 0 & 0 & 1 \\
$-\mathrm{V}$ & 1 & 0 & 1 & 0 & 0 & 0 \\
$-2 \mathrm{~V}$ & 1 & 0 & 1 & 1 & 0 & 0 \\
$-3 \mathrm{~V}$ & 1 & 0 & 1 & 1 & 1 & 0 \\
\hline
\end{tabular}


Fig. 4 Solar module PV characteristics for Soltech 1 STH-250 $\mathrm{W}$ a various irradiance at $25^{\circ} \mathrm{C} \mathbf{b}$ various temperature for $1000 \mathrm{~W} / \mathrm{m} 2$ irradiance

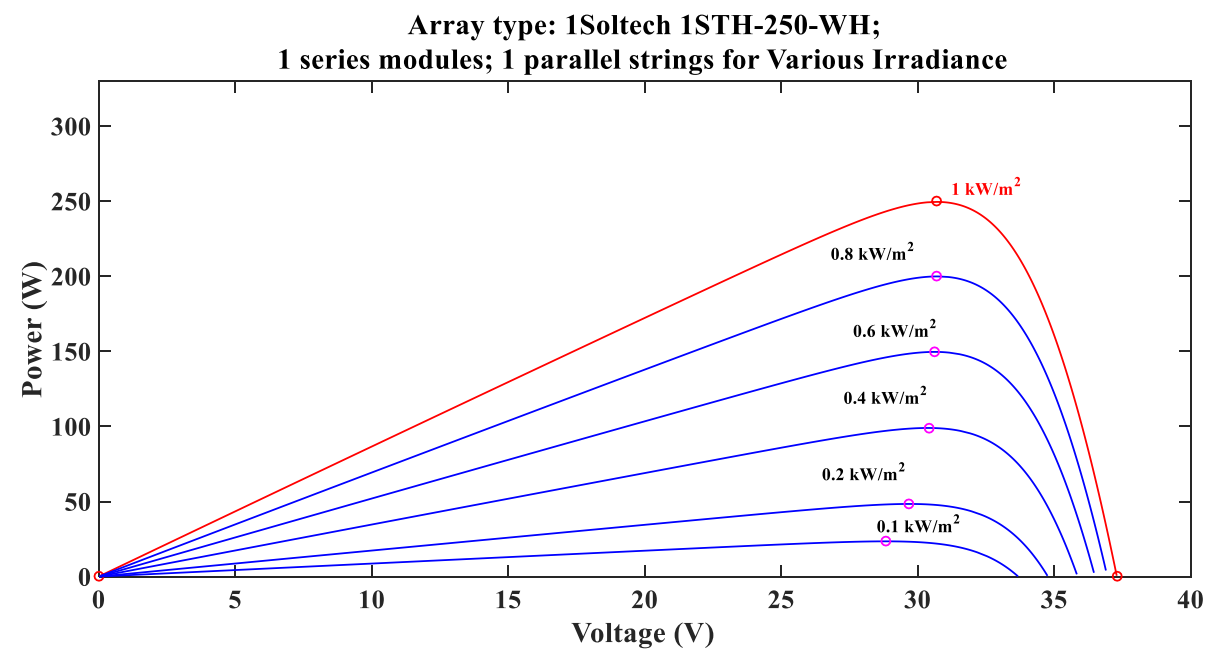

(a)

Array type: 1Soltech 1STH-250-WH;

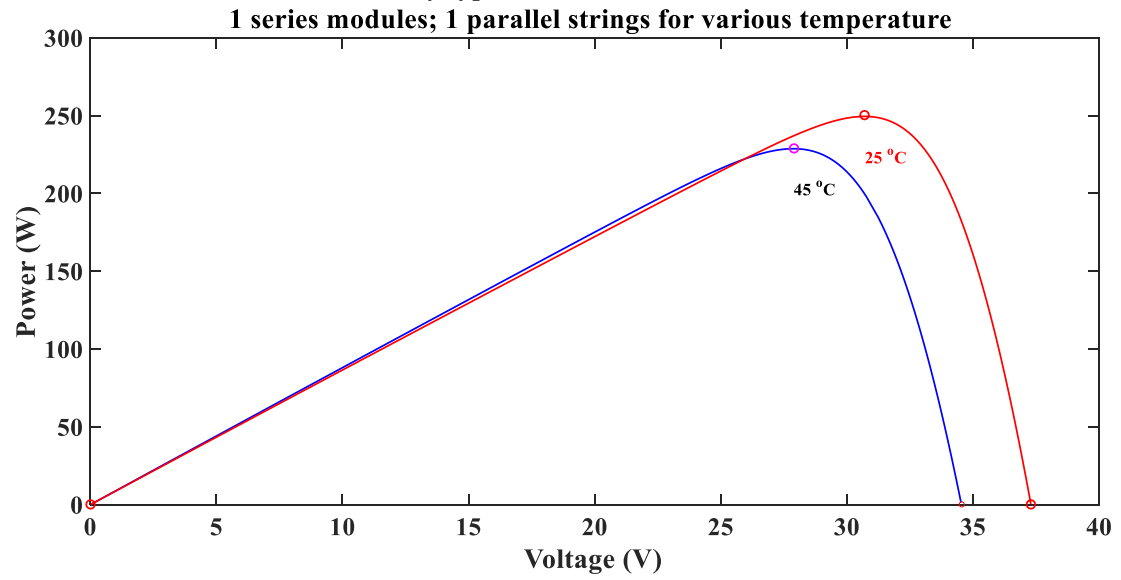

(b)
Table 2 Change in voltage as per irradiance and temperature

\begin{tabular}{lll}
\hline Irradiance $\left(\mathrm{Kw} / \mathrm{m}^{2}\right)$ & Temperature $\left({ }^{\circ} \mathrm{C}\right)$ & Maximum voltage (Volts) \\
\hline 1000 & 25 & 30.5 \\
800 & 25 & 30.4 \\
600 & 25 & 30.2 \\
400 & 25 & 30 \\
1000 & 45 & 27.82 \\
800 & 45 & 27.5 \\
600 & 45 & 27.2 \\
400 & 45 & 27 \\
\hline
\end{tabular}

$\cos 3 \theta_{1}+\cos 3 \theta_{2}+\cos 3 \theta_{3}=0$

$\cos 5 \theta_{1}+\cos 5 \theta_{2}+\cos 5 \theta_{3}=0$

For nine-level

$\cos \theta_{1}+\cos \theta_{2}+\cos \theta_{3}+\cos \theta_{4}=4 M$

$\cos 3 \theta_{1}+\cos 3 \theta_{2}+\cos 3 \theta_{3}+\cos 3 \theta_{4}=0$

$\cos 5 \theta_{1}+\cos 5 \theta_{2}+\cos 5 \theta_{3}+\cos 5 \theta_{4}=0$

$\cos 7 \theta_{1}+\cos 7 \theta_{2}+\cos 7 \theta_{3}+\cos 7 \theta_{4}=0$

where.

M-Modulating index in per unit.

$\theta_{1}, \theta_{2} \theta_{3}$ and $\theta_{4}$-switching angle for each bridge. 
The Eqs. 1, 2, and 3 and 4, 5, 6 and 7 are transcendental equations that are solved by using GSA adopted in [32], providing a solution as $\theta_{1}=10.41^{\circ}, \theta_{2}=30.32^{\circ}$ and $\theta_{3}=53.02^{\circ}$. Equation (8) represents the condition to be satisfied for the current to reach zero during the zero voltage level.

$\theta_{1}>\tan ^{-1}\left(\frac{\omega L}{R}\right)$

The load for design purposes is taken as predominantly resistive RL load as the IEEE STD 1547/UL 1741 states that the inverter circuit operates at unity power factor. The required reactive power and voltage control are obtained by installing a reactive power compensation system (RCS), generally an SVC or STATCOM. Thus the load has $R=100$ ohms and $L=25 \mathrm{mH}$, which gives a power factor of 0.94 lagging. This design also satisfies condition as $\tan ^{-1}\left(\frac{\omega L}{R}\right)$ is $8.93^{\circ}<10.41^{\circ}$.

The switches' ratings mainly consist of determination of peak voltage across switch and peak current through the switch. For the given circuit, the maximum current through the switches $I_{\text {max }}$ is $10.8 \mathrm{~A}$, and the maximum voltage across switch at steady state is $V_{\text {max }}$ is $108 \mathrm{~V}$. Thus, the switch selected by the above ratings is IRL650, whose voltage across the drain to source is $\left(\mathrm{V}_{\mathrm{ds}}\right) 200 \mathrm{~V}$ and drain current is $\left(I_{d}\right) 19$ A. IN4007 diode is selected.

Based on the parameters obtained from the datasheet, the RC snubber circuit is designed, and the obtained values for a damping factor of 0.65 are snubber inductance $L_{s}=0.6 \mathrm{mH}$ and snubber capacitor is $C_{s}=585 \mathrm{uF}$ with snubber resistance $R_{s}=41.6 \mathrm{Ohms}$. The snubber inductance is neglected as the load inductance is much higher.

\section{Simulation results}

The simulation study has been carried for both nine and seven level. A nine-level MLI is studied as the grid integration requires THD less than $8 \%$ for system voltage less than $1 \mathrm{kV}$ as per IEEE STD- 519 2014. A seven-level MLI has been implemented for development of FDI algorithm. The system is implemented in simulated in MATLAB-Simulink environment. The MPPT of the PV is obtained by employing Petrub and Observe (P\&O) algorithm. The PV terminal voltage, current and the power are shown in Fig. 5 . The time taken for settling at the steady state is 2 seconds. The output voltage is then provided to the proposed converter and the output voltage and current is shown in Fig. 6 . The output voltage and current is provided for an R load as it replicates the response of grid. The nine-level output voltage does not have a flat voltage as the terminal voltage of the PV is not constant. This ripple can be reduced by employing advance MPPT algorithms and maintaining the capacitor voltage of the DC-DC converter. The THD in terms of percentage for the nine-level operation of the converter is shown in Fig. 7. The THD for nine level proposed MLI with GSA based SHE with MPPT algorithm is shown in Fig. 7a. The lack of stiff voltage across capacitor causes certain asymmetry in the waveform that is reflected in THD. A nine-level MLI with DC source of $100 \mathrm{~V}$ is also studied. The output voltage along with THD is shown in Fig. $7 b$.
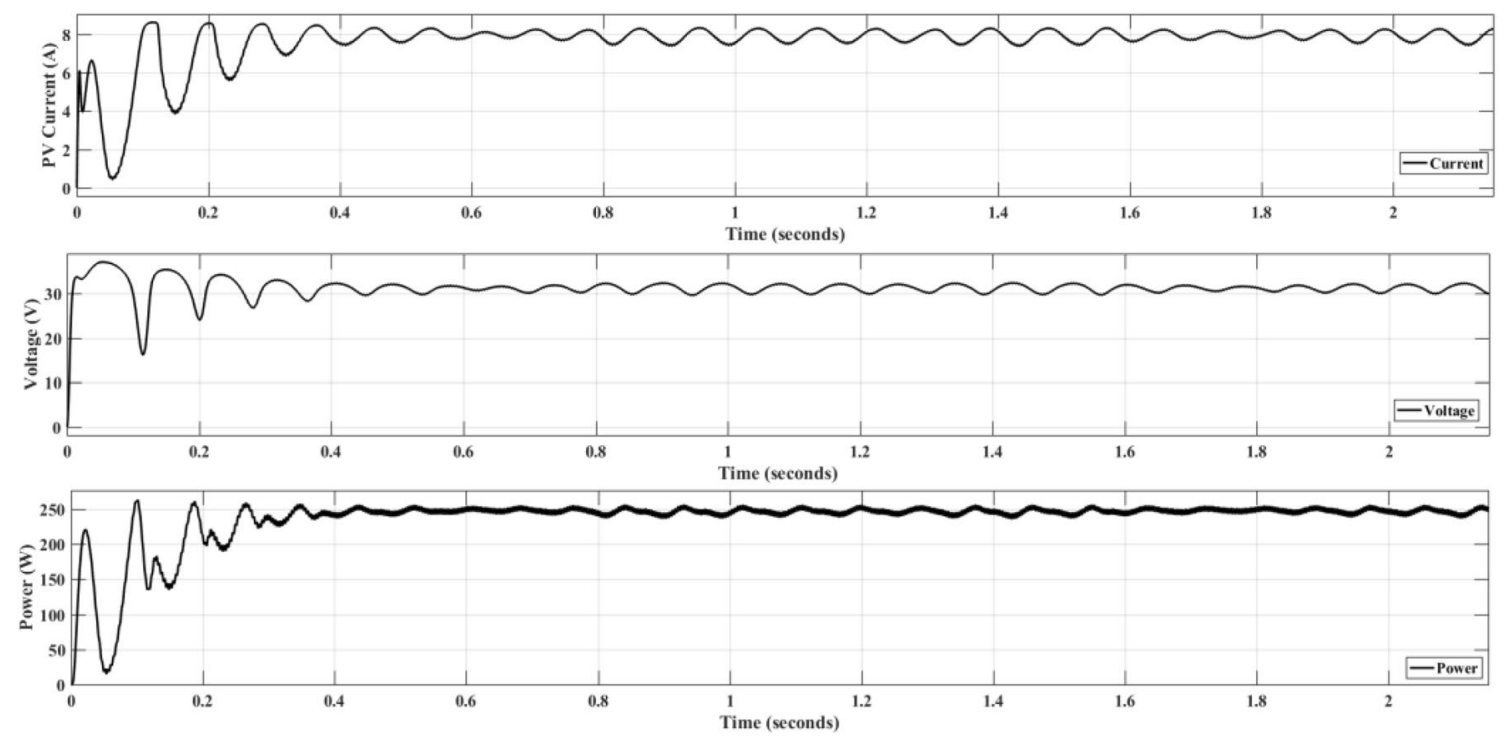

Fig. 5 Current, voltage and power of photo voltaic panel for maximum power point tracking 

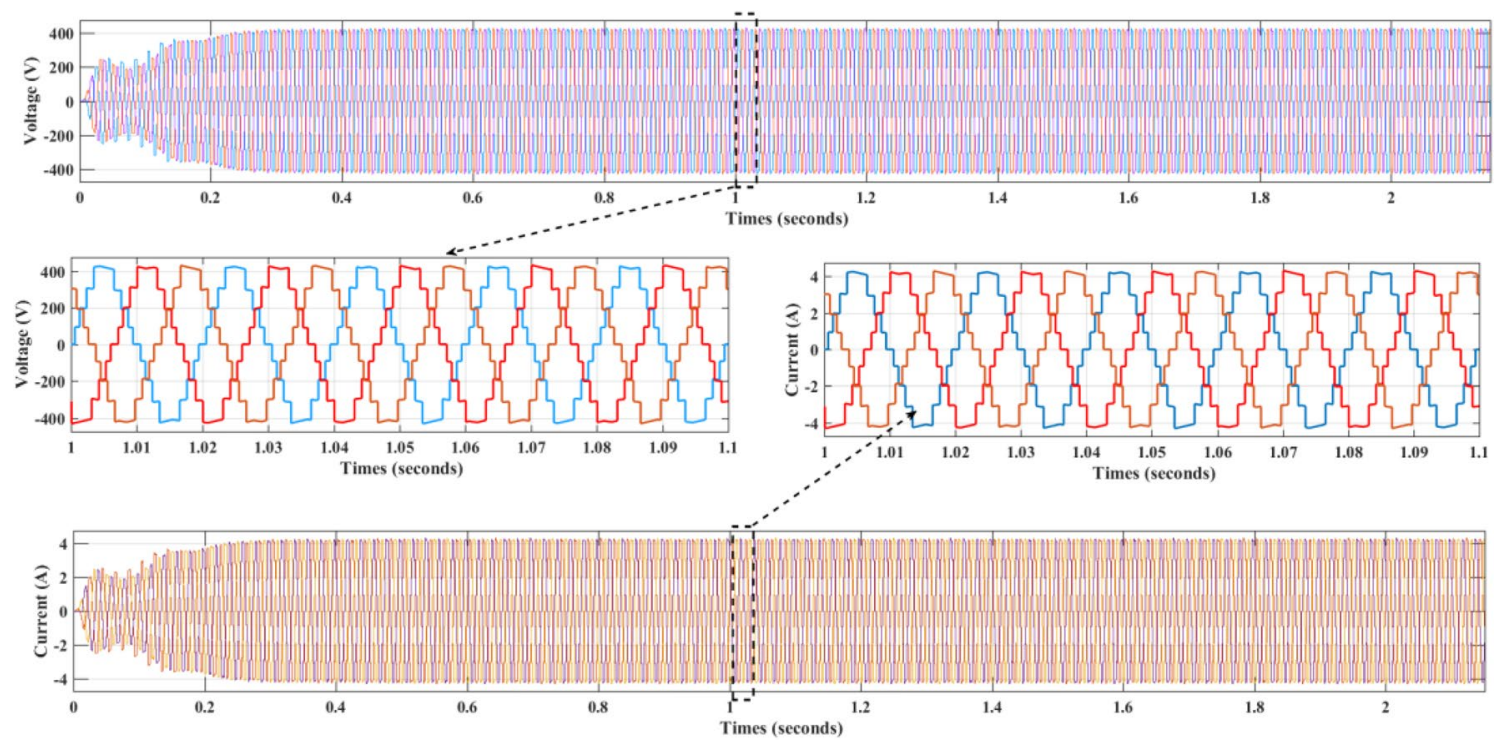

Fig.6 Simulation circuit of seven-level modified cascaded half-bridge MLI with PC
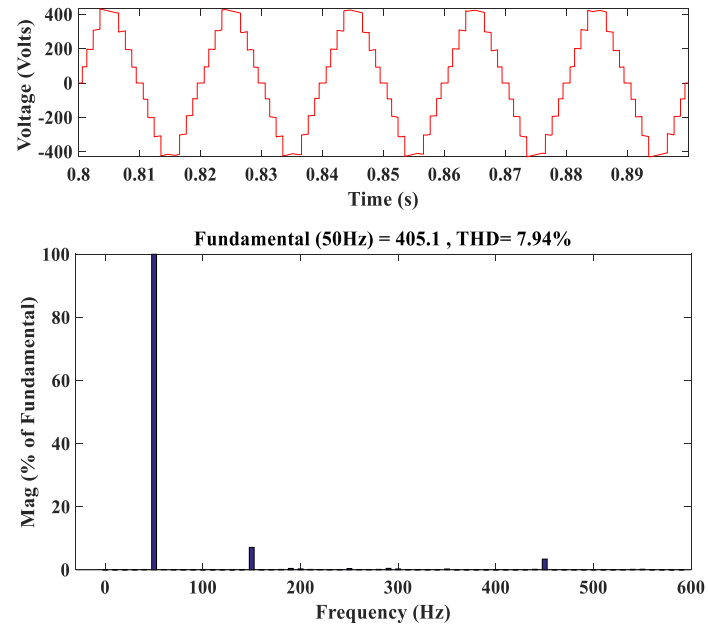

(a)
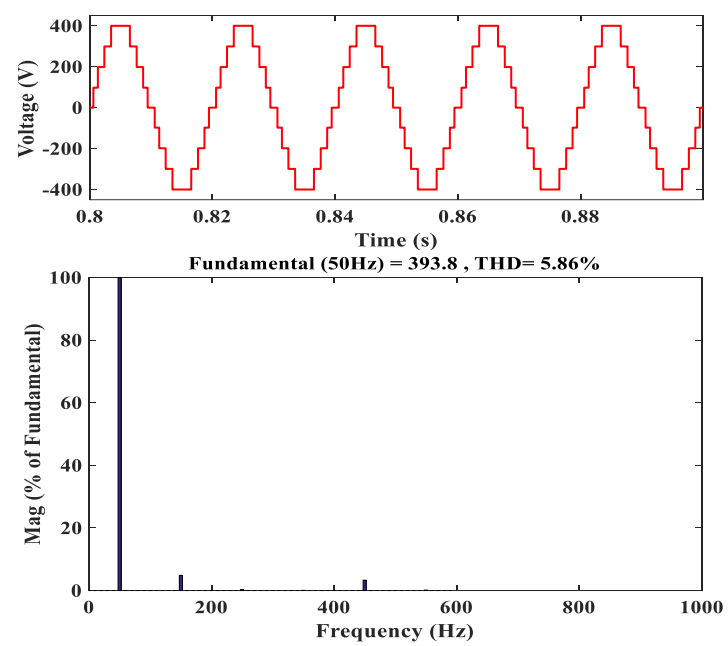

(b)

Fig.7 Percentage THD of nine-level proposed converter a with MPPT algorithm $\mathbf{b}$ with DC voltage source of $100 \mathrm{~V}$

The observed THD in both cases less than $8 \%$ and indiviual THD is less than $5 \%$, therefore in compliance with IEEE STD-519-2014 [33]. The analysis is also been carried for a seven level operation of the cproposed converter with a load current less than $1 \mathrm{~A}$. The terminal voltage and current for various types of load for seven level operation is shown in Fig. 8. An observation can be made that the output voltage waveform remains same irrespective of the load.

An open circuit fault is created by removing the switch and the effects of these faults on output voltage are analyzed. The output voltage waveform for each switch fault is shown in a-f in Fig. 9. From the waveforms, it can be concluded that.

- When either switch $P_{1}$ or $P_{3}$ is in fault conditions, then the waveform's symmetry is lost and the average voltage is positive as shown in Fig. 9b.

- When either switch $\mathrm{P}_{2}$ or $\mathrm{P}_{4}$ is in fault conditions, then the waveform's symmetry is lost and the average voltage is negative as shown in Fig. 9c.

- When switches $S_{1}, S_{2}$ and $S_{3}$ are in an open circuit fault condition, then the output voltage waveform proves 


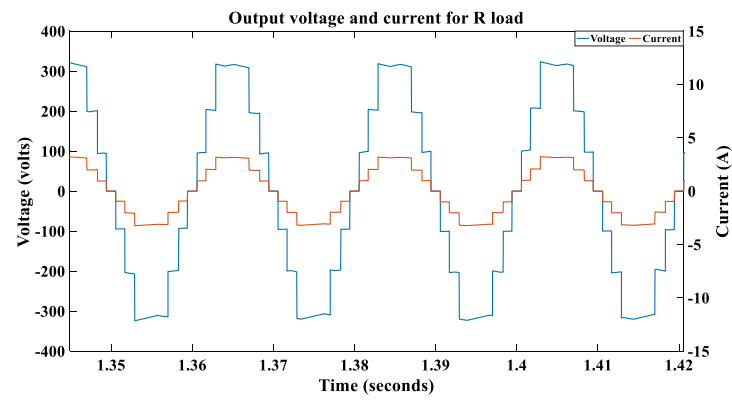

(a)

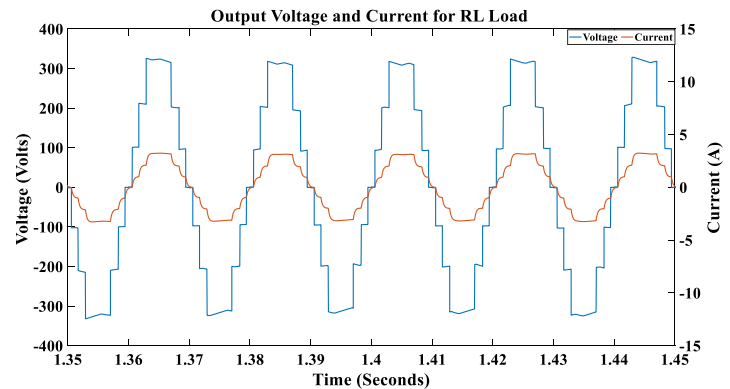

(b)

Fig. 8 Voltage and current waveforms of $\mathbf{a} R=100$ ohms $\mathbf{b} R=10$ ohms $L=25 \mathrm{mH}$

that fault isolation is an inherent characteristic of the proposed circuit as shown in Fig. 9d, e and f.

- When the fault occurs in $F$, the output voltage waveform is distorted due to the lagging inductive current. Since the inverter is generally operated at the unity power factor, the stress across the switch is less than other switches; therefore, F's probability of fault is low and there is no effect of fault in $\mathrm{F}$ on the voltage waveform for unity power factor operation.

\section{Fault detection and isolation scheme}

This circuit requires an FDI technique for its PC based on the above observations. Since the four switches present in the PC are critical to forming a closed-loop circuit, they are provided with redundancy. The fault detection technique employed for the switches in $P C$ is based on the average output voltage. The switches $P_{1}$ and $P_{3}$ are named here as a positive group and switches $\mathrm{P}_{2}$ and $\mathrm{P}_{4}$ are termed as negative group switches. The formula for average voltage is given by

$S=\frac{\sum_{i=0}^{N} V_{o i}}{N}$

when $S$ is between -1 and 1 there is no fault in the PC. When $S$ is greater than 1 , the negative group switches are in fault condition given by a binary variable labelled 'a.' Similarly, when $\mathrm{S}$ is less than -1 , the negative group switches are in fault condition given by a binary variable labelled 'b.'The non-critical switches should be detected so that troubleshooting is carried out. To detect the fault on the faulty switch Multi-Resolution Analysis (MRA) is carried out on the output voltage waveform as shown in Fig. 10.
This is due to the fact that the load voltage does not vary with the change in loads. The mathematical representation of MRA is presented in [19] defined as

$y_{a h}[n]=\sum_{k} h[k-2 n] x[k]$

$y_{a l}[n]=\sum_{k} g[k-2 n] x[k]$

where, $y_{a h}[n]$ and $y_{a l}[n]$ represent the output of high pass and low pass filters for signal $x[k]$ respectively.

The output voltage signals of the converter is subjected to MRA analysis and the output signals of low pass filter and high pass filter at level -1 is shown in Fig. 11. The open circuit faults in the MLI causes distortions in the output voltage waveforms. These distortions cause the changes in various harmonic components. In MRA the LPF and HPF are utilised to separate the low frequency components and high frequency components. The study of energy for these components can be correlated with the faults. The energy of the signal is calculated by adopting Parseval's energy theorem shown by Eqs. (12), (13), where $\mathrm{N}$ is number of samples. Similarly, the energy of approximate coefficients and detailed coefficients of the third level is calculated for each open circuit fault for various irradiance and temperature. From the obtained data, it is observed that only the first approximate and detailed coefficients are sufficient to identify the fault. The energy levels $E_{1}$ and $E_{0}$ for various open circuit faults in switches at different irradiance and temperature are shown in Table 3.

$E_{\text {level-1(HFP) }}=\sum_{n=1}^{N} y_{a h}[n]$ 


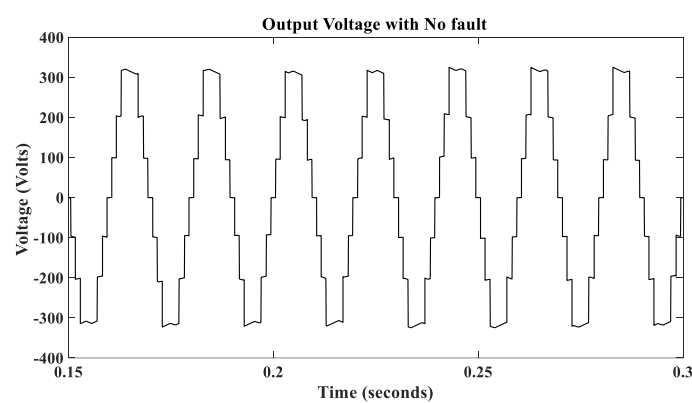

(a)

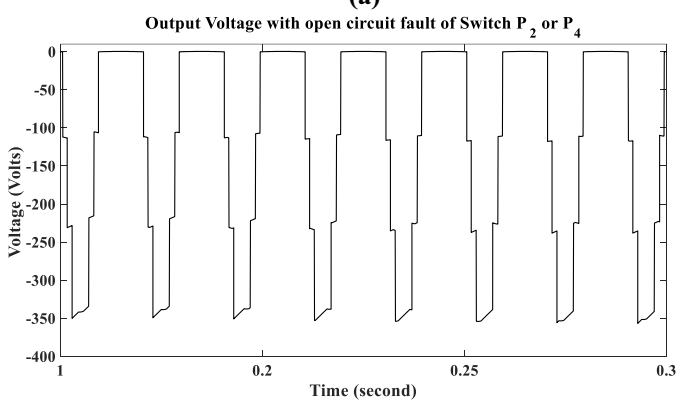

(c)

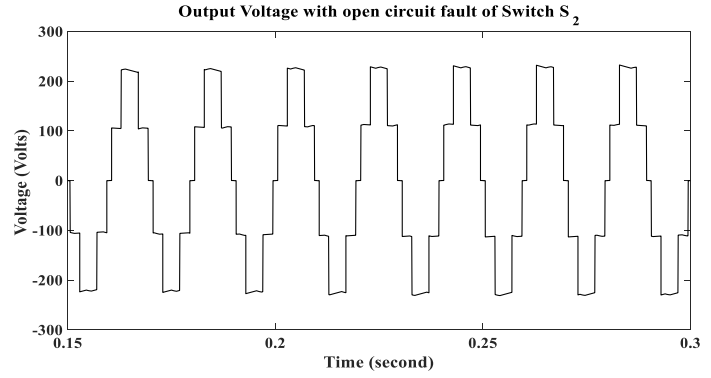

(e)

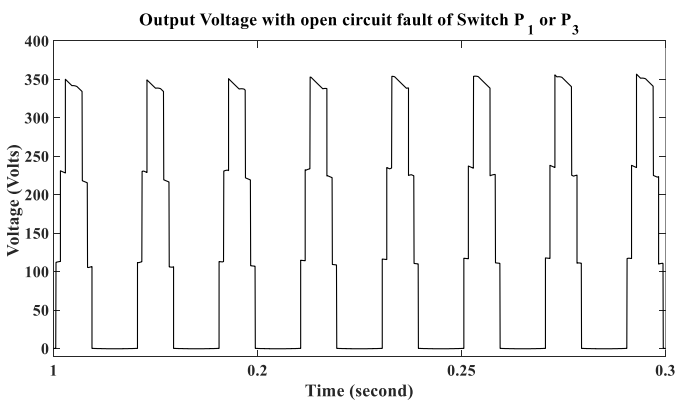

(b)

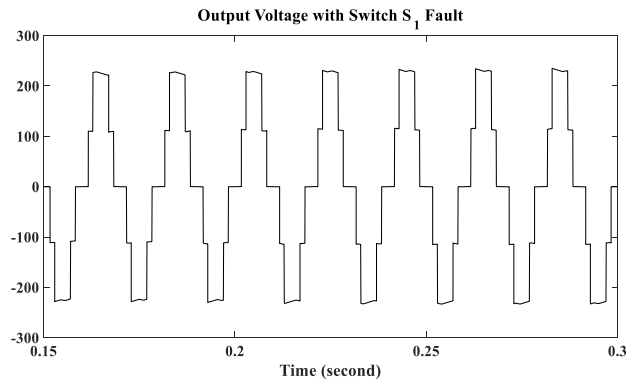

(d)

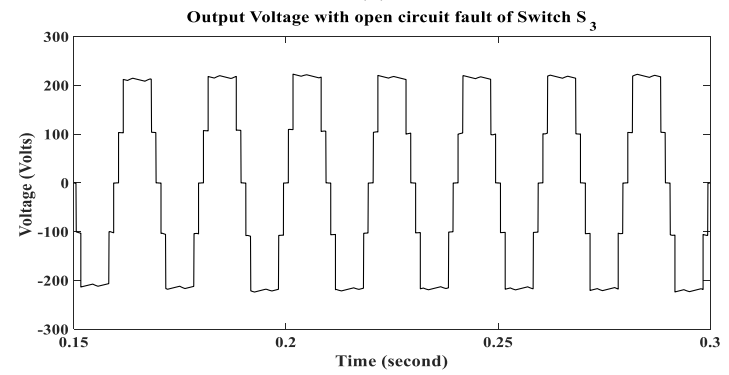

(f)

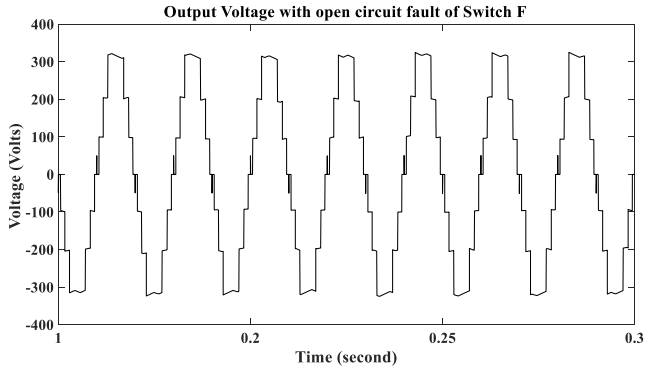

(g)

Fig. 9 Output voltage waveform for an open circuit fault condition in a No Fault b Switch $\mathrm{P}_{1}$ or $\mathrm{P}_{3}$ or both $\mathbf{c}$ Switch $\mathrm{P}_{2}$ or $\mathrm{P}_{4}$ or both $\mathbf{d}$ Switch $\mathrm{S}_{1}$ e Switch $\mathrm{S}_{2}$ and $\mathbf{f}$ Switch $\mathrm{S}_{3} \mathbf{g}$ Switch $\mathrm{F}$

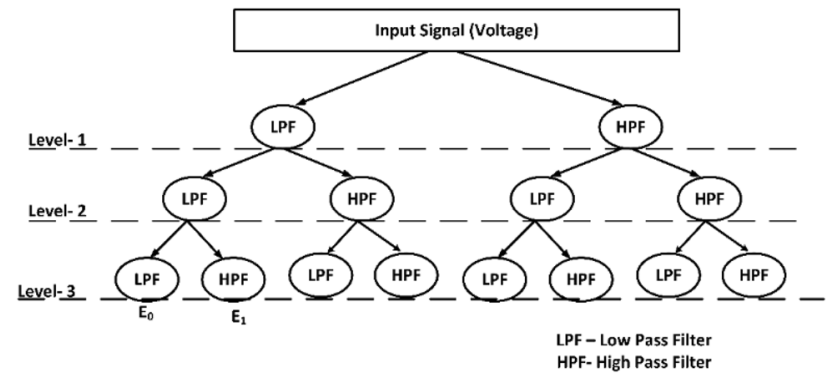

Fig.10 Multi resolution analysis of voltage signal up to level-3

$$
E_{\text {level-1(LFP) }}=\sum_{n=1}^{N} y_{a l}[n]
$$

The energy level No-Fault and open circuit fault of $F^{\prime}$ has overlapping values; thus, another energy level, $E_{1}$, is taken for the classification of fault, which is tabulated in Table 4. Based on the obtained data, an algorithm is developed to detect the fault shown as a flowchart in Fig. 12. The 


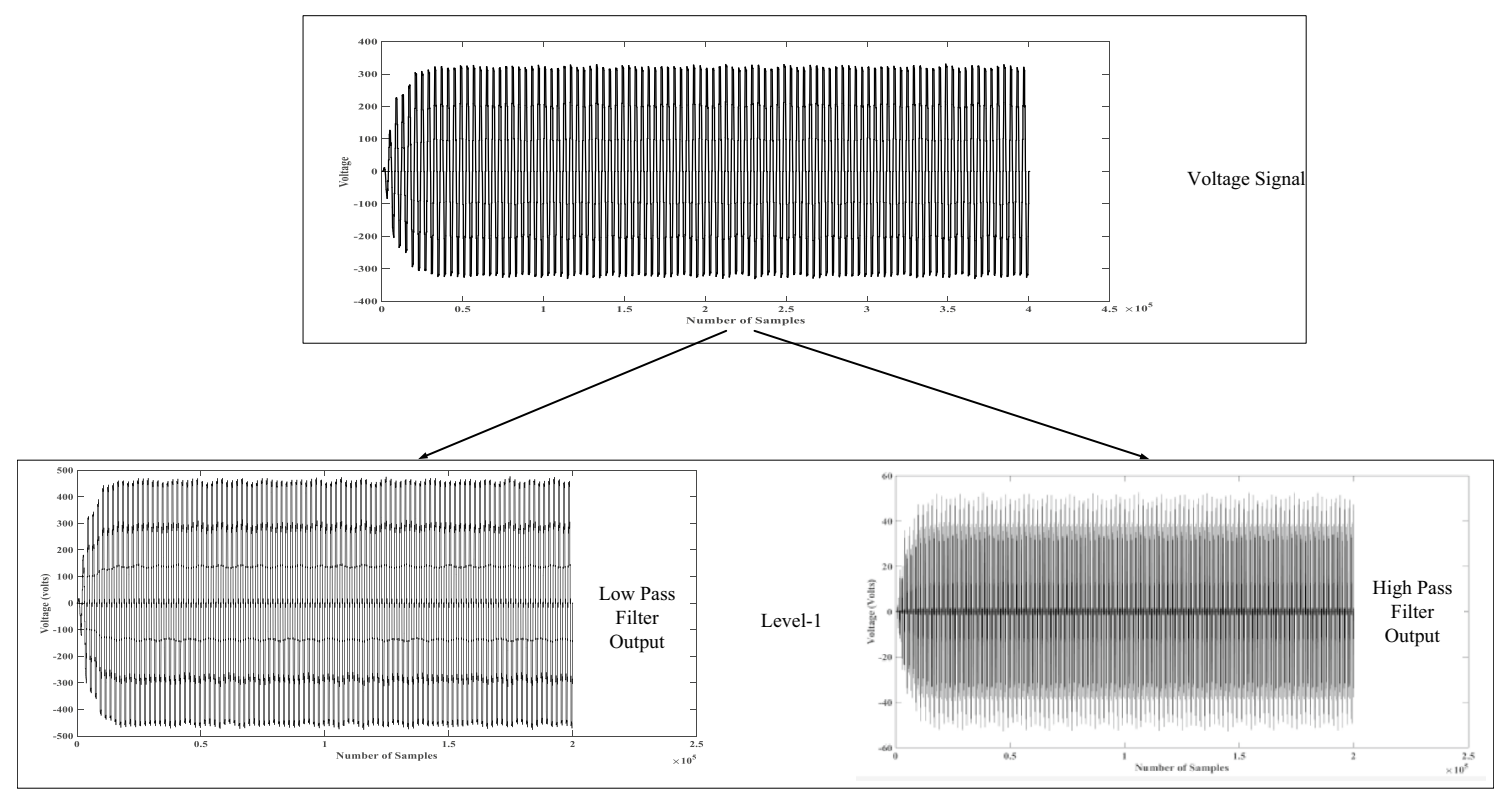

Fig.11 Multi resolution analysis for output voltage with no fault condition at $1000 \mathrm{w} / \mathrm{m}^{2}$ and $25^{\circ} \mathrm{C}$

Table 3 Energy levels for various open circuit fault

\begin{tabular}{|c|c|c|c|c|c|c|c|}
\hline \multirow{2}{*}{$\begin{array}{l}\text { Irradiance }\left(\mathrm{kwh} / \mathrm{m}^{2}\right) \text { and } \\
\text { temperature }\left({ }^{\circ} \mathrm{C}\right)\end{array}$} & \multirow{2}{*}{$\begin{array}{l}\text { PV panel maxi- } \\
\text { mum voltage }\end{array}$} & \multirow{2}{*}{$\begin{array}{l}\text { DC link capacitor volt- } \\
\text { age of one PV panel }\end{array}$} & \multicolumn{5}{|l|}{$E_{0}\left(V^{2} \sec ^{2} / m^{2}\right)\left(10^{4}\right)$} \\
\hline & & & no-fault condition & $\mathrm{S}_{1}$ fault & $\mathrm{S}_{2}$ fault & $\mathrm{S}_{3}$ fault & $F$ fault \\
\hline $1000 \& 25$ & 30.5 & 100 & 4.6740 & 1.9803 & 2.3537 & 2.9392 & 4.7589 \\
\hline $800 \& 25$ & 30.4 & 99.5 & 4.1784 & 1.9530 & 2.3448 & 2.8848 & 4.1805 \\
\hline $600 \& 25$ & 30.2 & 98.5 & 3.8509 & 1.8297 & 2.2098 & 2.8168 & 3.8779 \\
\hline $400 \& 25$ & 30 & 97 & 3.6669 & 1.8094 & 2.1878 & 2.7656 & 3.5544 \\
\hline $1000 \& 45$ & 27.82 & 94 & 3.5227 & 1.7801 & 2.1226 & 2.7530 & 2.6780 \\
\hline $800 \& 45$ & 27.5 & 93.5 & 3.4578 & 1.7138 & 2.0778 & 2.7197 & 2.6467 \\
\hline $600 \& 45$ & 27.2 & 93 & 3.2456 & 1.6516 & 2.0483 & 2.6432 & 2.4620 \\
\hline $400 \& 45$ & 27 & 92 & 3.0194 & 1.6188 & 2.0059 & 2.6234 & 2.4346 \\
\hline
\end{tabular}

Table 4 Energy levels for various open circuit fault

\begin{tabular}{lll}
\hline Irradiance $\left(\mathrm{kwh} / \mathrm{m}^{2}\right)$ and tem- & & \\
\cline { 2 - 3 } perature $(\mathrm{C} C)$ & No-fault & $\mathrm{F}$ \\
\hline $1000 \& 25$ & 17.08 & 25.47 \\
$800 \& 25$ & 14.21 & 23.9464 \\
$600 \& 25$ & 10.316 & 20.77 \\
$400 \& 25$ & 5.816 & 19.03 \\
$1000 \& 45$ & 15.089 & 26.0501 \\
$800 \& 45$ & 13.0099 & 22.0302 \\
$600 \& 45$ & 9.9102 & 19.56 \\
$400 \& 45$ & 5.67 & 18.6304 \\
\hline
\end{tabular}

$\operatorname{Max}\left(E_{0}\right.$ for fault in Switch $\left.S_{1}\right)<T F_{1}<\operatorname{Min}\left(E_{0}\right.$ for fault in Switch $\left.S_{2}\right)$

$\operatorname{Max}\left(E_{0}\right.$ for fault in Switch $\left.S_{2}\right)<T F_{2}<\operatorname{Min}\left(E_{0}\right.$ for fault in Switch $\left.S_{3}\right)$ 


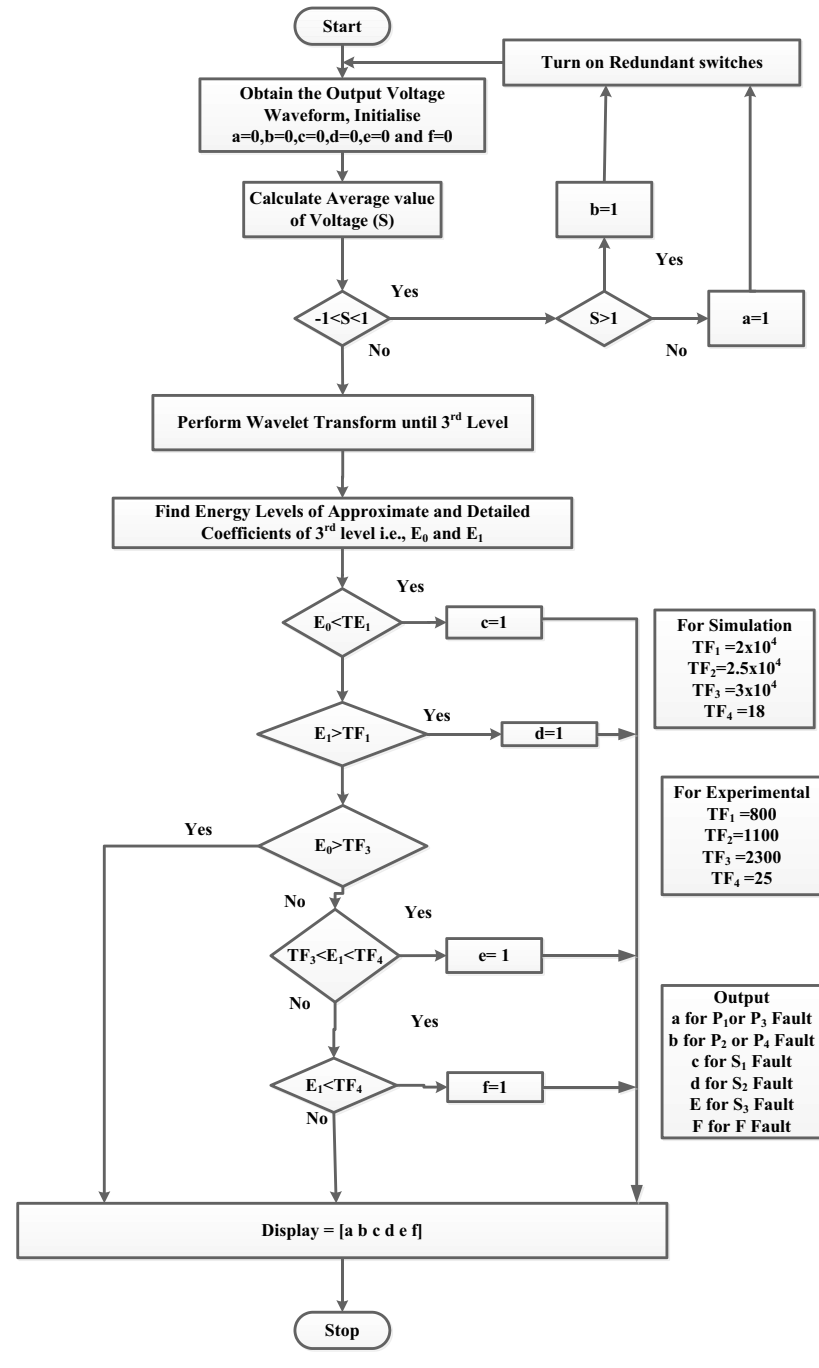

Fig. 12 Flowchart for detection of open circuit fault in switches

Table 5 Binary adaptation to represent a fault in switches
$\operatorname{Max}\left(E_{0}\right.$ for fault in Switch $\left.S_{3}\right)<T F_{3}<\operatorname{Min}\left(E_{0}\right.$ for No fault condition $)$

$\operatorname{Max}\left(E_{1}\right.$ No Fault condition $)<T F_{4}<\operatorname{Min}\left(E_{1}\right.$ for Fault for $\left.\mathrm{F}\right)$

The presented rule based FDI algorithm has output voltage as its input. The average of the voltage is initially checked to determine the conditions of switch in PC. The tolerance limit is kept between -1 to 1 to account for the asymmetry in waveform due to any transients during the operation. An MRA is done on the output voltage to find the approximate and detailed coefficients at level 3. Based on the energy levels and rules framed a decision is taken as shown in Table 6.

\section{Experimentation and validation}

A prototype of Modified cascaded MLI with PC has been developed in the laboratory with a DC source of supply of $30 \mathrm{~V}$, as shown in Fig. 13a. The considered output load is a resistive as the inverter connected to the PV power plant operates with a unity power factor. The output voltage is measured through an Agilent DS-1002 DSO is depicted in Fig. 13b. The data shows the output voltage has a frequency of $49.5 \mathrm{~Hz}$ with an error of $1 \%$ in frequency as the system is designed for $50 \mathrm{~Hz}$.This is, in turn connected to a PC a laptop. The output voltages are read by the PC and are subjected to the developed FDI algorithm. The experimental validation of FDI algorithm under various fault conditions is provided in Table 6. As the voltage level for the prototype is reduced compared to simulations the energy levels have also been altered. This alteration has caused the changes in the FDI scheme with respect to threshold values $\left(\mathrm{TF}_{1}, \mathrm{TF}_{2} \mathrm{TF}_{3}\right.$ and $\left.\mathrm{TF}_{4}\right)$ as shown in Fig. 12 . The results show that the developed fault detection algorithm is an effective method to detect faults.

\begin{tabular}{lllllll}
\hline Output & $\mathrm{a}$ & $\mathrm{b}$ & $\mathrm{c}$ & $\mathrm{d}$ & $\mathrm{e}$ & $\mathrm{f}$ \\
\hline No Fault & 0 & 0 & 0 & 0 & 0 & 0 \\
$\mathrm{P}_{1}$ or $\mathrm{P}_{3}$ & 1 & 0 & 0 & 0 & 0 & 0 \\
$\mathrm{P}_{4}$ or $\mathrm{P}_{2}$ & 0 & 1 & 0 & 0 & 0 & 0 \\
$\mathrm{~S}_{1}$ & 0 & 0 & 1 & 0 & 0 & 0 \\
$\mathrm{~S}_{2}$ & 0 & 0 & 0 & 1 & 0 & 0 \\
$\mathrm{~S}_{3}$ & 0 & 0 & 0 & 0 & 1 & 0 \\
$\mathrm{~F}$ & 0 & 0 & 0 & 0 & 0 & 1 \\
\hline
\end{tabular}


Table 6 Validation of fault detection algorithm from experimental results

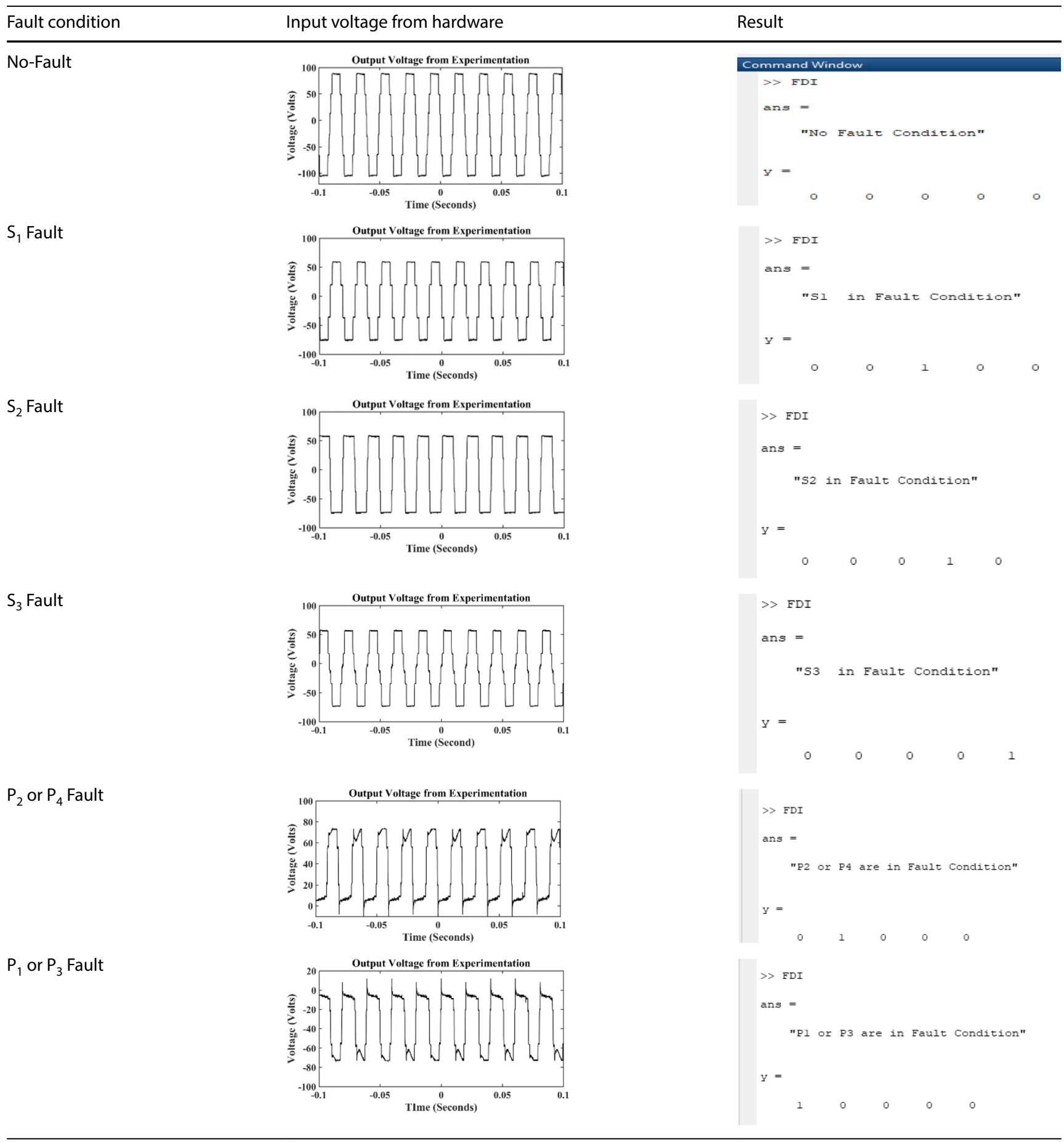




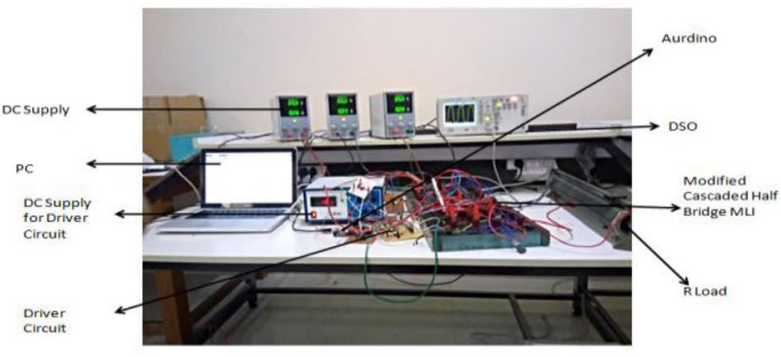

(a)

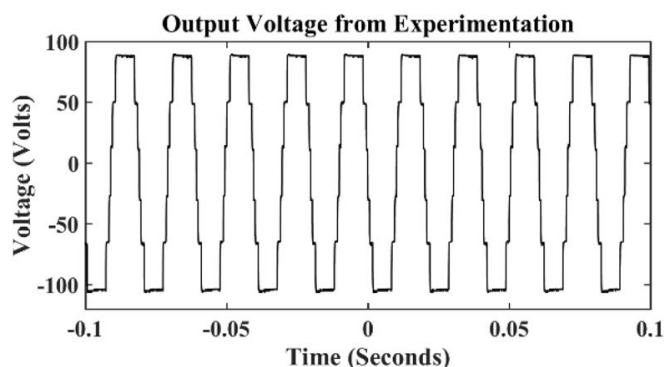

(b)

Fig.13 a Experimental setup of cascaded half-bridge MLI with PC $\mathbf{b}$ output voltage with no-fault

Table 7 Comparative analysis of MLI with proposed MLI

\begin{tabular}{lllllll}
\hline Ref. No & $\begin{array}{l}\text { Number } \\
\text { of levels }\end{array}$ & $\begin{array}{l}\text { Number of con- } \\
\text { trolled switches }\end{array}$ & $\begin{array}{l}\text { Number of redundancies } \\
\text { required for FDI per level }\end{array}$ & $\begin{array}{l}\text { Cost of } \\
\text { con- } \\
\text { verter }\end{array}$ & $\begin{array}{l}\text { Reduction in cost of } \\
\text { converter with proposed } \\
\text { converter without FDI (\%) }\end{array}$ & $\begin{array}{l}\text { Reduction in cost of } \\
\text { converter with proposed } \\
\text { converter without FDI (\%) }\end{array}$ \\
\hline$[23]$ & 9 & 16 & 6 & $16 x$ & 43 & 57 \\
{$[25]$} & 9 & 11 & 9 & $11 \times$ & 18 & 30 \\
{$[26]$} & 9 & 11 & 9 & $11 \times$ & 18 & 30 \\
{$[27]$} & 9 & 21 & 21 & $21 \times$ & 57 & 67 \\
{$[28]$} & 9 & 12 & 12 & $12 x$ & 25 & 42 \\
{$[29]$} & 9 & 12 & 12 & $12 x$ & 25 & 42 \\
{$[30]$} & 9 & 12 & 12 & $12 x$ & 25 & 42 \\
Proposed & 9 & 9 & 5 (irrespective of number of & $9 x$ & 0 & 0 \\
Con- & & levels) & & & \\
verter & & & &
\end{tabular}

cost of the converter. The comparative analysis is shown in Table 7. For the comparison purpose the cost of converter is calculated solely based on the switch. This comparison considers the cost of each switch controlled switch along with driver circuit is considered ' $x$ '. The comparison does not consider the cost of diodes as their cost is significantly lower compared to the controlled switch.

\section{Conclusion}

The proposed Modified Cascaded Half-Bridge MLI with PC with $\frac{m+9}{2}$ has the least number of switches when compared with topologies present in literature. This circuit has an inherent fault isolation property. Due to its low number of switches, it requires less complicated control and fewer driver circuits. This reduces the overall cost of MLI when compared to other RPC-MLI. The proposed MLI has a high potential for adoption in PV power plants as an integral part of transformerless and filterless system with the above advantages. A Petrub and Observe algorithm is utilized to track the maximum power point. The response time of the algorithm is 2 seconds. A nine-level and seven level version of proposed converter has been simulated in MATLAB. The THD for a proposed for nine level MLI is $7.94 \%$ with PV input and $5.86 \%$ with constant DC input due to adoption of SHE method solved by the GSA algorithm. The obtained THD is within the limits set by IEEE STD-519-2014 for system under $1 \mathrm{kV}$ of line.

This paper concentrates on the development of an MLI with a reduced number of switches and a high possibility of fault isolation. A simple FDI algorithm for all the controlled switches has been proposed based on the obtained energy levels of the third level approximate and detailed coefficient obtained by the application of MRA to the output voltage. Table 7 provides a comparison of proposed converter and other RPC-MLI in terms of number of switches and fault isolation capability.

During open circuit faults, the voltage level and power supplied by the system reduce; thus, proper energy management systems and voltage controlling devices such as SVC and STATCOM are required, which also acts as reactive power sources for the inverter. If a fault occurs in one halfbridge of a particular phase in three-phase systems, then 
corresponding switches in another phase will be removed to provide a balanced supply. The energy levels of switch 'F'are dependent on load, as load does not remain constant in a PV power plant system, another technique needs to be developed for the fault detection of Switch 'F.'The work has to be further enhanced for a practical implementation by considering following issues.

- A grid integration algorithm has to be studied such that a proper power flow can be controlled.

- The MPPT algorithm can be integrated in the power control algorithm and further studies on the PWM technique has to be designed so that the DC-DC converter can be eliminated.

- Further improvement has to be done such that the stop in voltage level due to fault condition does not affect the performance.

\section{Declarations}

Conflict of interest The authors declare that they have no conflict of interest.

Open Access This article is licensed under a Creative Commons Attribution 4.0 International License, which permits use, sharing, adaptation, distribution and reproduction in any medium or format, as long as you give appropriate credit to the original author(s) and the source, provide a link to the Creative Commons licence, and indicate if changes were made. The images or other third party material in this article are included in the article's Creative Commons licence, unless indicated otherwise in a credit line to the material. If material is not included in the article's Creative Commons licence and your intended use is not permitted by statutory regulation or exceeds the permitted use, you will need to obtain permission directly from the copyright holder. To view a copy of this licence, visit http://creativecommons. org/licenses/by/4.0/.

\section{References}

1. Choi NS, Cho JG, Cho GH (1991) A general circuit topology of multilevel inverter. https://doi.org/10.1109/pesc.1991.162660

2. Lai JS, Peng FZ (1996) Multilevel converters-a new breed of power converters. IEEE Trans Ind Appl. https://doi.org/10.1109/ 28.502161

3. Tolbert LM, Peng FZ, Habetler TG (1999) Multilevel converters for large electric drives. IEEE Trans Ind Appl 35(1):36-44. https:// doi.org/10.1109/28.740843

4. Meynard TA, Foch $H$, Thomas P, Courault J, Jakob R, Nahrstaedt M (2002) Multicell converters: basic concepts and industry applications. IEEE Trans Ind Electron. https://doi.org/10.1109/TIE.2002. 803174

5. Silva P, Munoz J, Aliaga R, Gaisse P, Restrepo C, Fernandez M (2016) On the DC/DC converters for cascaded asymmetric multilevel inverters aimed to inject photovoltaic energy into microgrids. https://doi.org/10.1109/SPEC.2016.7846160

6. Arulkumar K, Vijayakumar D, Palanisamy K (2015) Modeling and control strategy of three phase neutral point clamped multilevel PV inverter connected to the grid. J Build Eng. https://doi.org/ 10.1016/j.jobe.2015.06.001

7. Sridhar V, Umashankar S (2017) A comprehensive review on CHB MLI based PV inverter and feasibility study of CHB MLI based PVSTATCOM. Renew Sustain Energy Rev. https://doi.org/10.1016/j. rser.2017.04.111

8. Trabelsi M, Bayhan S, Ghazi KA, Abu-Rub H, Ben-Brahim L (2016) Finite-control-set model predictive control for grid-connected packed-u-cells multilevel inverter. IEEE Trans Ind Electron. https://doi.org/10.1109/TIE.2016.2558142

9. Yang S, Bryant A, Mawby P, Xiang D, Ran L, Tavner P (2011) An industry-based survey of reliability in power electronic converters. IEEE Trans Ind Appl 47(3):1441-1451. https://doi.org/ 10.1109/TIA.2011.2124436

10. Yang S, Xiang D, Bryant A, Mawby P, Ran L, Tavner P (2010) Condition monitoring for device reliability in power electronic converters: a review. IEEE Trans Power Electron 25(11):2734-2752. https://doi.org/10.1109/TPEL.2010.2049377

11. Prejbeanu R, Roman M, Ivanov V, Radu A (2020) Simulation and fault detection techniques for multilevel inverters used in smart grids. https://doi.org/10.1109/ICCC49264.2020.9257216

12. Bocaniala C, Costa J, Bumbaru S (2005) On the applicability of state-of-the-art fault diagnosis methodologies to simple and complex systems. Ann Dunarea de Jos 2005:33-38

13. Vyas UB, Srivani SG (2017) Role of soft computing techniques in fault detection of switches in multilevel inverter. Int J Pure Appl Math 114(10):467-476

14. KhomfoiS, Tolbert LM (2007) Fault detection and reconfiguration technique for cascaded $\mathrm{H}$-bridge 11-level inverter drives operating under faulty condition. In: Proceedings of the International Conference on Power Electronics and Drive Systems, pp. 1035-1042. https://doi.org/10.1109/PEDS.2007.4487831

15. Ahmed M, Sheir A, Orabi M (2018) Asymmetric cascaded halfbridge multilevel inverter without polarity changer. Alexandria Eng J 57(4):2415-2426. https://doi.org/10.1016/j.aej.2017.08. 018

16. H. Mhiesan et al., (2018) A method for open-circuit faults detecting, identifying, and isolating in cascaded h-bridge multilevel inverters. https://doi.org/10.1109/PEDG.2018.8447855

17. Raj N, Anand A, Jagadanand G, George S (2020) Development and experimental validation of fault detection and diagnosis method in SPWM modulated symmetric cascaded $\mathrm{H}$-bridge multilevel inverter. Int J Power Electron 11(3):409-426. https:// doi.org/10.1504/IJPELEC.2020.106229

18. Srivani SG, Vyas UB (2018) Fault detection of switches in multilevel inverter using wavelet and neural network. In: 2017 7th International Conference on Power Systems, ICPS 2017 pp. 151-156. https://doi.org/10.1109/ICPES.2017.8387284

19. Keswani RA, Suryawanshi HM, Ballal MS (2015) Multi-resolution analysis for converter switch faults identification. IET Power Electron 8(5):783-792. https://doi.org/10.1049/iet-pel.2014.0450

20. Manjunath TG, Kusagur A (2018) Analysis of different meta heuristics method in intelligent fault detection of multilevel inverter with photovoltaic power generation source. Int J Power Electron Drive Syst 9(3):1214-1222. https://doi.org/10.11591/ijpeds.v9.i3. pp1214-1222

21. Raj N, Jagadanand G, George S (2018) Fault detection and diagnosis in asymmetric multilevel inverter using artificial neural network. Int J Electron 105(4):559-571. https://doi.org/10.1080/ 00207217.2017 .1378382 
22. Mhiesan H, Wei Y, Siwakoti YP, Mantooth HA (2020) A fault-tolerant hybrid cascaded h-bridge multilevel inverter. IEEE Trans Power Electron 35(12): 12702-12715. https://doi.org/10.1109/ TPEL.2020.2996097

23. Chappa A, Gupta S, Kumar L, Gupta KK (2020) A fault-tolerant multilevel inverter topology with preserved output power and voltage levels under pre and post-fault operation. IEEE Trans Ind Electron. https://doi.org/10.1109/TIE.2020.2994880

24. Anand A, Raj N, George S, Jagadanand G (2016) Open switch fault detection in cascaded $\mathrm{H}$-bridge multilevel inverter using normalised mean voltages. https://doi.org/10.1109/ICPES.2016. 7584128

25. Su GJ (2005) Multilevel DC-link inverter. IEEE Trans Ind Appl. https://doi.org/10.1109/TIA.2005.847306

26. Babaei E, Laali S, Bayat Z (2015) A single-phase cascaded multilevel inverter based on a new basic unit with reduced number of power switches. IEEE Trans Ind Electron. https://doi.org/10. 1109/TIE.2014.2336601

27. Toupchi Khosroshahi M (2014) Crisscross cascade multilevel inverter with reduction in number of components. IET Power Electron. https://doi.org/10.1049/iet-pel.2013.0541

28. Gupta KK, Jain S (2014) A novel multilevel inverter based on switched dc sources. IEEE Trans Ind Electron. https://doi.org/10. 1109/TIE.2013.2282606
29. Mokhberdoran A, Ajami A (2014) Symmetric and asymmetric design and implementation of new cascaded multilevel inverter topology. IEEE Trans Power Electron. https://doi.org/10.1109/ TPEL.2014.2302873

30. Babaei E, Alilu S, Laali S (2014) A new general topology for cascaded multilevel inverters with reduced number of components based on developed H-bridge. IEEE Trans Ind Electron. https:// doi.org/10.1109/TIE.2013.2286561

31. Sridhar V, Umashankar S (2017) A comprehensive review on CHB MLI based PV inverter and feasibility study of CHB MLI based PV-STATCOM. Renew Sustain Energy Rev 78:138-156. https:// doi.org/10.1016/j.rser.2017.04.111

32. Rao JV, Mahesh A (2017) Firing angle optimization of sevenlevel cascaded $\mathrm{H}$-bridge multilevel inverter with un-equal DC sources using GSA approach. https://doi.org/10.1109/POWERI. 2016.8077389

33. Roger DMFG (2014) IEEE recommended practice and requirements for harmonic control in electric power systems. IEEE Std 2014: 519-2014

Publisher's Note Springer Nature remains neutral with regard to jurisdictional claims in published maps and institutional affiliations. 